\title{
Student Teamwork: Developing Virtual Support for Team projects
}

\author{
Janice Whatley, J.E.Whatley@salford,ac,uk
}

\begin{abstract}
In the $21^{\text {st }}$ Century team working increasingly requires online cooperative skills as well as more traditional skills associated with face to face team working. Virtual team working differs from face to face team working in a number of respects, such as interpreting the alternatives to visual cues, adapting to synchronous communication, developing trust and cohesion and cultural interpretations. However, co-located student teams working within higher education can only simulate team working as it might be experienced in organisations today. For example, students can learn from their mistakes in a non threatening environment, colleagues tend to be established friends and assessing teamwork encourages behaviour such as "free-riding". Using a prototyping approach, which involves students and tutors, a system has been designed to support learners engaged in team working. This system helps students to achieve to their full potential and appreciate issues surrounding virtual teamwork. The Guardian Agent system enables teams to allocate project tasks and agree ground rules for the team according to individuals' preferences. Results from four cycles of its use are presented, together with modifications arising from iterations of testing. The results show that students find the system useful in preparing for team working, and have encouraged further development of the system.
\end{abstract}

\section{Keywords:}

Software Agent, Teamwork, Virtual teamwork, Prototyping, Student learning, Higher Education.

\section{Introduction}

Team working is an important skill for undergraduate students to acquire, whilst studying in higher education. Many organisations use teamwork extensively to produce results, particularly in systems development and software engineering. Within global organisations, members of staff are separated physically, but often required to work as a team. Team working as a virtual team is possible using computer mediated communication and the Internet, and different skills are required in order to achieve effective team working online. In this paper a software system for supporting team working is described. This system will help students to acquire virtual team working skills in a co-located context. This will be useful within large colocated organisations, where they may rely on this type of software, as well as helping to prepare students for virtual team working in a global workplace. The development of this system has been advised through prototyping at various stages, and involving students and tutors in the modifications incorporated at each stage.

\section{Related work}

Although team working is used extensively in higher education to provide an opportunity to acquire team working skills, cited in key skills literature as "working with others", there has been little work to date on how the skills acquired in a colocated campus setting relate to using these skills in a global setting. This section examines some of the literature on global team working and using team working in the educational setting, followed by a brief look at existing support software, such as groupware. 


\subsection{Global Team Working}

One of the current learning outcomes for undergraduate programmes is to prepare students for working globally in today's world, in particular, working in a virtual team or group (Watson-Manheim, Chudoba et al. 2002; Sheppard and Dominick 2003). Team working has become an important element of our provision for students, offering them the opportunity to acquire essential team working skills. Global or virtual project teams, who communicate with each other using the Internet, are becoming commonplace in the global world, so our approaches should perhaps also reflect these changes in the working environment (Paul, Seetharaman et al. 2004).

Virtual team working differs from face to face team working in a number of respects, such as interpreting the alternatives to visual cues, adapting to computer mediated communication, developing trust and cohesion and cultural interpretations (Jarvenpaa and Leidner 1998).

"The move to virtual work is the most dramatic change in the nature of the small group since humans acquired the capacity to talk to each other" (Lipnack and Stamps 2000).

Differences between working in a virtual or global team or a face to face team are called discontinuities by Watson-Manheim et al, but they also identified a number of similarities, called continuities, which make research more complex, and found that there was limited research to date on the whole area of virtual team or group working (Watson-Manheim, Chudoba et al. 2002). The importance of global teams and developing global leaders is emphasised by Maznevski and DiStefano, who suggest that mapping, bridging and integrating are important processes in global teams, i.e. understanding differences between the team members, active communication to overcome the differences and bringing the different perspectives together (Maznevski and DiStefano 2000).

\subsection{Team Working on Campus}

Students often struggle to achieve the desired learning outcomes from team working, because they are under considerable pressures to complete learning activities to strict deadlines and other commitments make organising meetings and using communications effectively problematical. Within the contrived environment of a team project a number of other factors also play a part in sharing the work between the team members, such as friendship, favouritism, a lack of skills. In particular, previous research has found that team members not contributing, or adverse group dynamics, resulting from a close relationship with their peers, may be significant in a team project, as well as lack of time, experience and skills (Whatley, Staniford et al. 1999). A bad team working experience will prevent team members from reaching the 'Norming' and 'Performing' stages of group working (Tuckman 1965). 'Norming' is important for group cohesion, as group members recognise the need to accept rules for working together, an essential precursor for effective performance on the tasks of the project. Livingstone and Lynch suggest that empowering students in their team working, by providing resources, support and some challenge in their project, will overcome the feeling of loss of control, which often fuels negative feelings about team working (Livingstone and Lynch 2000). The benefits of cooperative learning to students more than compensate for the problems that arise when working in a team. Once students get over their negative reactions, they achieve deeper learning and become more positive about their subjects and themselves (Felder and Brent 1994). 
Accepting the importance of teaching group working in Higher education, how we teach elements of this becomes an issue, forming the groups and assigning roles to members is critical. Membership may be assigned randomly, or by self-selection, but roles within the group play an important part in promoting learning within the group project. Group roles may be management or task areas, corresponding to the maintenance or task orientation suggested by Hartley. Management roles may include leader, recorder or time-keeper, and may be randomly assigned (Millis and Cottell 1997), but in order to realise learning outcomes for individual students, are better assigned according to abilities or skills needs. Similarly, the task areas could be assigned according to preferences expressed by the students, or proposed by the tutor.

Team working within a higher education institution can only give a simulation of organisational team working, for example students can learn from their mistakes in a non threatening environment, colleagues tend to be established friends and assessing teamwork encourages behaviour, such as "free-riding", that may be contrary to the notion of group cohesion. These factors lead to considerations of the ethical suitability of using online collaboration in education, and what can be done to minimise the resulting difficulties in developing good group dynamics (Johnson, Suriya et al. 2002).

Sheppard and Dominick provide a framework of key factors influencing engineering students when doing team projects, including team structures, objectives, skills, motivation, trust, conflict, which are common to co-located team working, but also cultural norms, technology, communication, cross-cultural understanding, which apply in different ways to virtual teams (Sheppard and Dominick 2003). Many of these factors are similarly identified by Bohemia in his comparison of co-located and virtual teams (Bohemia 2004).

Successful group working requires that the maintenance roles (process) as well as the task roles (product) of the group are given attention (Hartley 1998; Bohemia 2004). Group dynamics play an important role in determining how successful the outcome of the project is, i.e. the ways in which the members interact with each other and how this changes with time as the group develops (Bion 1961), (Gibbs 1995), (Jaques 1984). Gilly Salmon (Salmon 2000)) presents ways in which tutors can help students to interact socially online, in order to develop group cohesion. Most important in developing group cohesion is agreeing group norms, or ground rules, i.e. rules of behaviour produced through social interaction, that become frames of reference for group members (Hartley 1998).

\subsection{Software for supporting team working}

Software has been designed to help with team working, generically called "groupware", it enables several people to access and work on the same sets of information even though physically distributed, and has been specifically designed to help "goal directed group work" (George and Jessup 1997), and with an emphasis on enriching meetings on group projects. Indeed much of the literature implies that the task roles of team projects are helped by using groupware, e.g. (Jessup and Valacich 1993). Corbitt and Martz further say that task and group processes are supported by such technology, but they question whether the more social aspects, or maintenance roles, are similarly supported, and these are needed for developing trust and maintaining openness in relationships (Corbitt and Martz 2003). There is evidence to show that student support using commercial groupware products enables 
communication between team members and instructors (Tiwari and Holtham 1998), but does not necessarily promote cohesion between team members.

In previous research, students' perceptions of the manner in which their team worked together in a face to face setting, confirmed that teams were more likely to be successful in their projects if they pay attention to some of the social aspects or maintenance roles of team working, such as setting groundrules, defining roles or helping everyone contribute (Whatley, Staniford et al. 1999). So a system that provides a richer interaction than groupware, to promote the maintenance roles of team working is proposed, in order to engender awareness and appreciation of the other team members they are working with.

\section{Designing the Guardian Agent to Support Team Working}

Using an action research and prototyping approach this work is investigating whether a system to support campus-based learners engaged in team working can help learners to appreciate some of the issues surrounding virtual teamwork. Because there are few examples of online team working within higher education, it was necessary to work with campus-based students to elicit the requirements of a supporting software system. Prototyping was chosen as a suitable method for development, not only because its benefits include speed of development, lower cost and simplicity, but also because user involvement would enable the researchers to build up the requirements of the system, as different functions were incorporated (Nickolls 1993).

The proposed system is called a Guardian Agent, because, like a "guardian angel", it would provide personal guidance, by working quietly in the background on each team member's workstation. An agent-based system was suggested for this support, as an agent is a self-contained, concurrently executing software process, which encapsulates the current state in terms of knowledge, and is able to communicate with other agents through message passing (Wooldridge 1995). Hence an agent system will be able to mediate between the team members, storing information about individual members and the progress of the project, and passing appropriate information to members as required in the course of the project work.

Initially the designers looked at these possible solutions that a software agent may provide:

a) An impartial onlooker to help students to make decisions on team working;

b) Software support for supporting students by bridging the divide between time and place. Students may prefer to work at times to suit themselves, so the software support can keep track of the students' progress on the work, and enable all students to be aware of the status of the project;

c) Suggest actions the team should take to progress the project.

The first iteration of the agent-based system was designed to elicit information about individual team members' preferences and abilities, to enable a project team to allocate the project tasks equitably. Later iterations also gathered information on individuals' priorities for ground rules for the team, and suggested rules that all members will agree with. In is envisaged that once the project plan has been set, the agent system will inform students of the progress of the project and monitor activities towards the project objectives in future iterations of the system development. Table 1 gives a brief list of possible roles for an agent system at the three main stages of the team project. 
Table 1 - Roles identified for the Guardian Agent at each stage of the group project.

\begin{tabular}{|l|l|}
\hline Project stage & Potential areas in which Guardian Agent can help \\
\hline Planning & $\begin{array}{l}\text { Introductions, individual preferences } \\
\text { Setting ground rules } \\
\text { Produce a project plan }\end{array}$ \\
\hline Doing the project & $\begin{array}{l}\text { Check the time schedule } \\
\text { Ensure all members contribute } \\
\text { Identify lack of skills }\end{array}$ \\
\hline Completing & $\begin{array}{l}\text { Collating the individual parts } \\
\text { Preparing a report } \\
\text { Appraising the group's performance }\end{array}$ \\
\hline
\end{tabular}

The agent system will autonomously monitor the progress of the team project, and has the potential to suggest ways in which the students can act to improve the progress of the project and enhance the communication between members of the team.

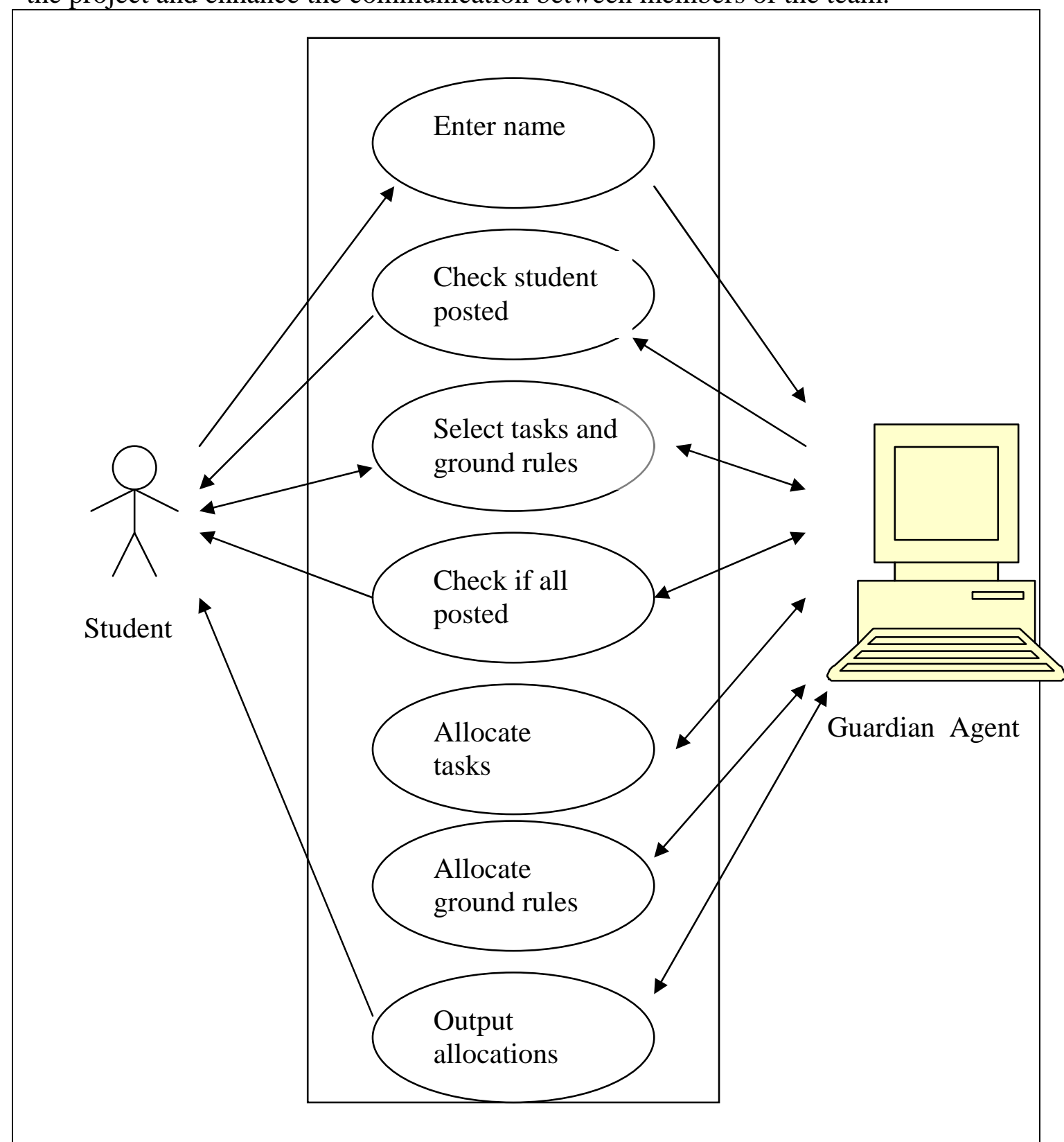

Figure 1 - Use case diagram showing part of the interaction with the Guardian Agent 
The agent system has been developed through several prototypes, and is now implemented as a MySQL database with PHP coding for the interface. In this way the data about each student is stored in a central repository, for searching and access to information (Figure 1). This implementation also makes the agent system accessible over the Internet, essential for distributed teams, but also useful for our ISI students.

The premise is that by eliciting information about team members, and storing it for easy retrieval, team members will gain a better awareness and appreciation of each other, leading to improved interpersonal relations. Knowledge about other team members' abilities leads to trust that an individual is capable and willing to undertake particular tasks. Similarly, knowing that most team members agree with the selected ground rules, encourages everyone to adhere to them, again leading to better trust that outputs will be achieved in a timely manner.

It is not proposed that such an agent will replace the tutor's input, or the team leader role, but the agent will perform some of the administrative tasks, which are usually performed in a natural way by the team members during face-to-face meetings, but are more difficult when distributed. The agent will simply provide a mechanism to help the team to agree upon the allocations of tasks, by providing readily accessible information upon which decisions can be based.

The agent system has been developed to concentrate on the project planning stage, starting with providing introductions in the form of individual preferences for tasks (Table 1). Early versions were pre-programmed with a single set of skills, including technical skills such as programming and web design as well as skills generally applicable to any project, so students only used the agent system once to give their preferences. Ground rules were introduced in the version used in 2003, also changing to code the system in Java with a MySQL database.

The current implementation of the agent system was expanded to help students to think about team structuring and norms for communication. It includes a wider range of skill areas, divided into project generic and more specific ones, so now provides the following main functions:

Allocation of project skills, which apply to any type of project;

Allocation of project skills specific to the particular domain and Agreement of ground rules for the team to work together.

There now follows a description of the system as it has been used in the 2005/6 teaching year. After the system has been described, the process leading up to this implementation will be explained.

The project teams involved in this development are composed of between 12 and 15 undergraduate students, taken from the first, second and final years of an undergraduate programme in Business Informations Systems or Information Technology. A leader and deputy are appointed, who take responsibility for running the project, with guidance from a team tutor. The Guardian Agent has been set up with a name and leader for each of the 20 or so teams. It is pre-set with a list of generic skills for projects and ground rules. In the first week of Semester 1, the team leader enrols each of the team members onto the system, and all of the team members can log on, set up a password, and use it. Each student in the team considers their abilities and preferences for the list of generic skills associated with any type of team project, ranking each one on a scale from Like to Dislike and Poor to Good (Figure 2). 


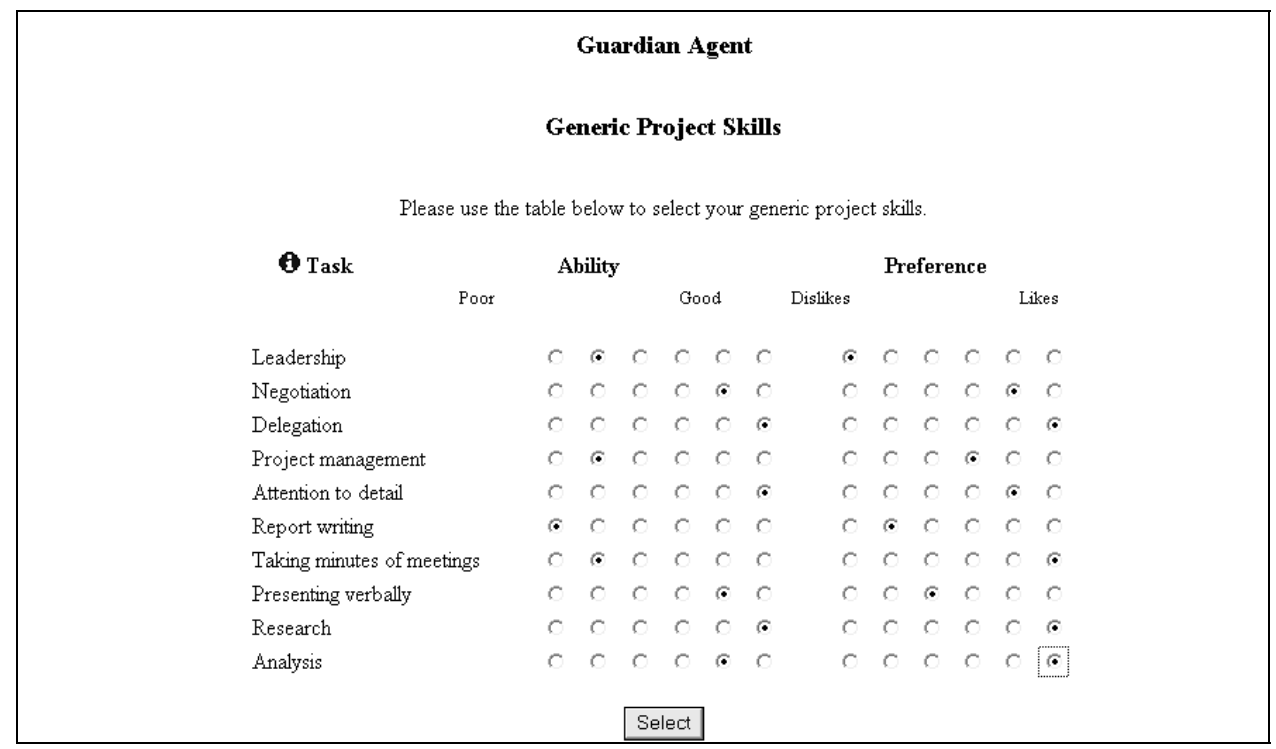

Figure 2 - Setting project generic skills preferences

The agent system next asks the student to consider which of a set of ground rules they consider to be important to work with as a team (Figure 3).

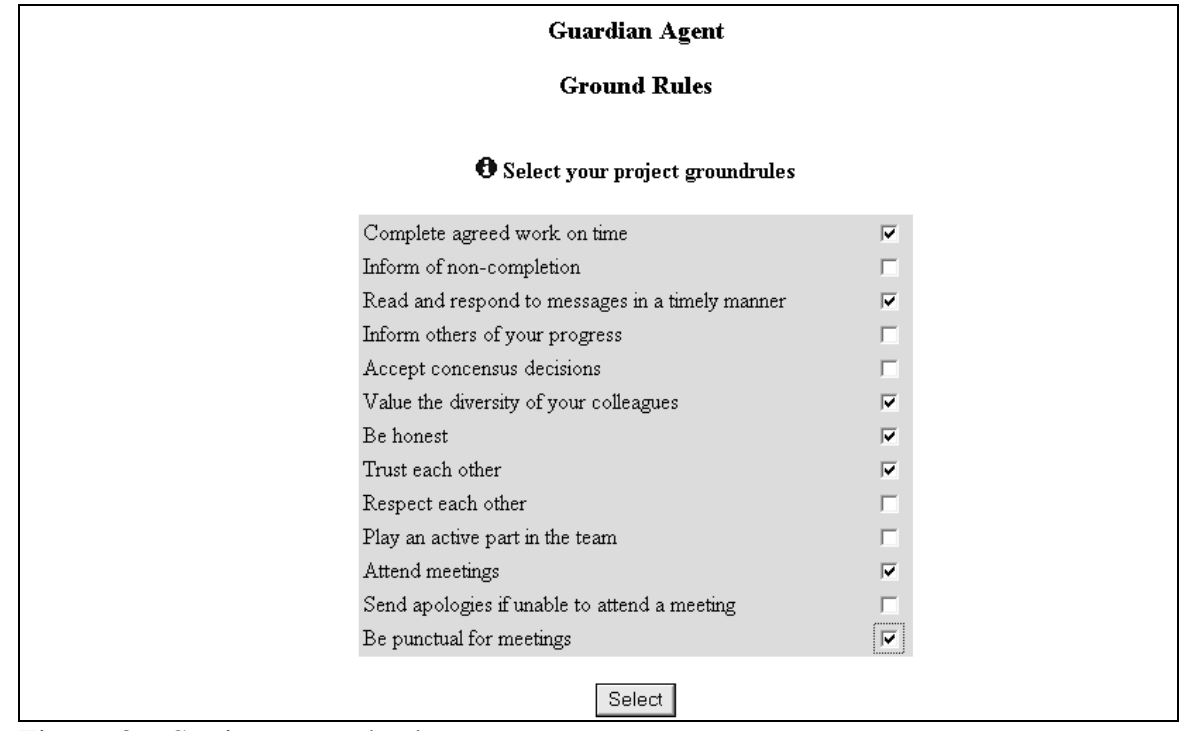

Figure 3 - Setting ground rules

When all of the students have posted their preferences, the team leader is able to look at the suggested allocations the Guardian Agent has arrived at (Figure 4). The team leader can use these as a basis for making decisions as to who should carry out the generic project skill areas, and whether any training is suggested. In the case of the ISI project teams many team leaders have previously sub-divided their teams into technical and administrative areas, on the basis of an informal interview with each of their team members. The agent recommendations can be used instead of these interviews, or may be used as additional information to help the team leader to allocate tasks.

The suggestions of ground rules is based on the suggestion that a ground rule should be adopted if more than half of the team members agree with it. From the example shown in Figure 4, more than half of the team members agreed that it is important to be punctual for meetings, so the Guardian Agent returns this as an allocation. 


\begin{tabular}{|c|c|c|c|}
\hline \multicolumn{4}{|c|}{ Project Specific Skills allocation } \\
\hline Username & Skill & Ability & Preference \\
\hline septcol & Multimedia design & Good & Likes \\
\hline septcol & Programming - PHP & Good & Likes \\
\hline septcol & Macromedia Dreamweaver & Good & Likes \\
\hline septann & HCI design for applications & Good & Likes \\
\hline septann & Microsoft Project & Good & Likes \\
\hline septann & Macromedia Dreamweaver & Good & Likes \\
\hline septbob & Multimedia design & Good & Likes \\
\hline septbob & Macromedia Dreamweaver & Good & Likes \\
\hline septmike & Web design & Good & Likes \\
\hline septmike & Multimedia design & Good & Likes \\
\hline septmike & Microsoft Project & Good & Likes \\
\hline septmike & Macromedia Dreamweaver & Good & Likes \\
\hline \multicolumn{4}{|c|}{ Project Specific Skills allocation after training } \\
\hline Username & Skill & Ability & Preference \\
\hline septcol & HCI design for applications & Needs training & Likes \\
\hline septann & Web design & Needs training & Likes \\
\hline septmike & Programming - HTML & Needs training & Likes \\
\hline & \multicolumn{2}{|c|}{ Groundrules allocated to the group } & \\
\hline & \multicolumn{2}{|c|}{ Groundrule } & \\
\hline & \multicolumn{2}{|c|}{ Be punctual for meetings } & \\
\hline
\end{tabular}

Figure 4 - suggested allocations from Guardian Agent

By this stage in the Team Projects, the team have an understanding of what the project involves, and at this point the team leader is ready to consider what specific skills are required for the project. The team leader chooses appropriate skills from a list, ready for the agent system to be used for a second time by all of the team members, to select their preferences and abilities from this list, in the same way as before. The team leader is then able to allocate project tasks to team members on the basis of the Guardian Agent's suggestions for allocation and for allocation after training.

\section{The prototyping development process}

The users of such an agent system are the students themselves, including team leader roles, as well as tutors and administrators. As a result, a number of technology, interface and pedagogical considerations are pertinent for the different users. By considering the different users' feedback and suggestions for modifications from questionnaires, interviews and focus groups, subsequent prototypes have arisen, to take these into account.

In testing prototypes of the system with campus-based students, the researchers wanted to identify factors causing most difficulties in developing group cohesion for these students, such as bad attendance or poor work quality. The researchers were also looking for feedback on how team leaders used the system to allocate tasks, compared to previously, general acceptance levels of the system from team members' and team leaders' perspectives, suggestions for other functions and whether they thought the system might be suitable for online teams.

The system was tested with between 6 and 10 of the project teams each year (just under half). Team leaders and deputies were interviewed to gain an insight into the processes used for the team project, and in many cases comparisons were made between the outcomes after using the agent system and outcomes previously attained without using the agent system. All team members who used the system were asked to complete a short questionnaire, asking their opinions on the usefulness of the system. A focus group was also run, inviting feedback from all students who had used the system. 
A summary of the questionnaire results from the four cycles of the Guardian Agent trials are given in Table 2. In addition to the quantitative results presented, there was much informative feedback, used, alongside the interview and focus group findings, to alter subsequent versions of the agent system. To explain the table columns, in 2002 the agent was written in Prolog, using a dedicated server to store the data, but owing to the inflexibility of this arrangement, subsequent versions had a client-server architecture, which proved more satisfactory. The Java version was updated to a PHP version in the last two years. In 2004, additional functionality was introduced as a result of our investigations into the ways in which team leaders and the team decide upon the skills for their projects. As all of the projects are different, we decided that it would be better to encourage the teams to start thinking about the general nature of their project in the first weeks of the term, and the project generic skills would be used at this stage. After the team had decided upon their possible solution they would be in a position to decide upon project specific skills required to develop their solution, so the project specific skills would be used at this later stage. The allocation of ground rules was introduced as a response to feedback from team members that teams were having difficulty building group identity and cohesion. Figures showing a result over $50 \%$ have been emboldened for clarity of reading.

Guardian Agent

Summary of Questionnaire results 2002 to 2005

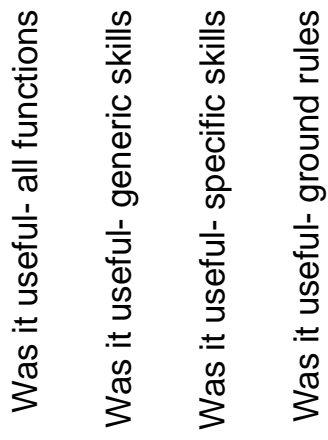

Year

Prolog 2002

Number answering Yes 26

$\%$ of total respondents $\quad \mathbf{5 3}$

Java 2003

Number answering Yes 13

$\%$ of total respondents $\quad \mathbf{5 9}$

PHP 2004

Number answering Yes

$\%$ of total respondents

PHP 2005

Number answering Yes

$\%$ of total respondents

Table 2 - Summary of questionnaire results from 4 cycles of trials

The table shows that each year over half of the students thought the system had been useful to them. Although the project skills were deemed as useful, several teams did not look at the ground rules at all. Overall the interface was regarded as satisfactory to use, but interestingly, few students felt that the Guardian Agent needed to have a character, such as that of the Microsoft Office Assistant. Most students did appreciate 
that the system would be useful for online team working, but did not regard it as being as much use when students meet face to face in their teams, and fewer that half of the respondents indicated a wish to use it in the future, a finding explored further in the focus groups.

The following discussion of the results from the interviews is structured around the five main question areas:

how it was used in their project;

implementation and functions;

skills and ground rules included;

other functions GA could do and

willingness to use it again in future years.

\section{How the teams used the agent system}

Feedback suggests that team leaders thought the agent provided valuable information on members' skills and preferences, which was good for forming the structure of the team.

“...helped me to know who to put into which part of the team ..."

In some cases a paper based audit of individual's skills provided the basis for a team structure, before the agent was used, and respondents reported that the agent output and their allocations did agree closely. Team leaders remarked that it was good for identifying training needs, either individuals who liked something but felt they were not very good at it, or by returning no allocations for a skill area.

\section{Feedback on the implementation}

Most students and team leaders agreed that the system was simple and easy to use.

"...good, straightforward and basic, and led the user through it..."

Later versions had an improved layout for presenting the allocations, and an ability to choose between output by person or by skill. They would also like to have a printable version. Although there are instructions for using the agent available as a Word document, brief guidance onscreen would be preferable.

\section{The skills and ground rules pre-programmed}

Both the project generic and specific skill areas were regarded as a good selection for most projects. The ground rules were considered to be comprehensive to most respondents, even though in the past the notion of agreeing ground rules is not usually considered by our students in the ISI.

"...by looking at the groundrules, the team had a better understanding of team working, and I based the contract on them..."

A few respondents said that including ground rules did get the team thinking about their means of communication and how they work with each other, indeed some team leaders reported improved team spirit, with less conflict.

\section{Suggestions for other functions}

Suggestions included help with minutes of meetings, progress reports, applying deadlines, use of a calendar and linking the agent outputs with project management software. Formalised contracts seemed to help the teams to get started on the project, perhaps including contact details within the agent system would be useful. Some suggested it would be useful to be able to edit team members' skill preferences and abilities, as they learn a new skill, and so build up skills on the database from one semester and one year to the next. 


\section{Willingness to use the Guardian Agent in the future}

All team leaders interviewed said they definitely found it a useful tool, and would use it again. Even team leaders who did not use it with their team thought it would have been useful, and wished they had persevered with the agent system in the first weeks of the semester. The response from team members, shown in the analysis of the questionnaire, was not as enthusiastic as team leaders, because the role of allocating tasks to team members tends to be invisible to team members, and few team members looked at the allocations output from the Guardian Agent to find out about their fellow team members' abilities and preferences. However, team members did recognise that the Guardian Agent system would be most useful for teams working online. As a result we will promote a greater awareness of its usefulness by introducing it to all students before the projects begin in September.

One team leader pointed out that the ISI team projects are not like real work, where money motivates team members and there are procedures in place for dealing with poor quality of work. Research into team working using student teams may not be transferable to work teams, bringing a different set of discontinuities into play (Watson-Manheim, Chudoba et al. 2002). But team leaders would welcome a system that can help to promote team cohesion, and can help the team leader to control work quality and attendance.

The results from this research indicate that the Guardian Agent system can go some way towards preparing students for working in virtual teams, by providing some experience of using online means to learn about each other's abilities and considering ground rules for working together. This agent system also has potential to help distance learning students to work together on team projects, an area little investigated so far. Certainly, students on campus, although able to have face to face communication, have reaped the benefit of using this agent system in their team projects.

\section{5. $\quad$ Future Trends}

In a small way this agent system is introducing to our students an alternative way in which computer mediated communication tools can be used for collaborative working. This agent system has the potential to be developed further, following an iterative prototyping method of development as has been used in this work. In particular the agent system can give a better understanding of other team members, communicating differences between members and bringing team members together to help promote good group dynamics. It seems to help all team members to "buy into" the project, encouraging active participation, which should encourage team cohesion, but to what extent trust is promoted by this system is yet to be established.

\section{Conclusions}

In this paper a software agent system has been described, which was designed through an iterative prototyping process. The agent system was tested over four iterations of development, and by involving the student users in the development process, each subsequent version incorporated further functionality as suggested by the users.

The findings from this research indicate that the Guardian Agent system is something that students on campus could benefit from, as well as online students. For campus based students it can be developed to provide experience of some of the tools commonly used for virtual teamwork, and provide a bridge between these tools and more social aspects of teamwork, which can sometimes prevent virtual teams from achieving their full potential. The agent system as described represents a small subset 
of the possible functions that such an agent system could provide, and further user feedback will determine the priorities of developing these functions.

\section{References:}

Bion, W. (1961). Experiences in groups. London, Tavistock.

Bohemia, E. (2004). Working collaboratively in todays global environment: a global product development course? International engineering and product design education conference, Delft, The Netherlands.

Corbitt, G. and B. Martz (2003). "Groupware case studies: trust, commitment and the free expression of ideas." Team Performance Management 9(1/2): 16-22.

Felder, R. and R. Brent (1994). Cooperative Learning in Technical Courses: Procedures, Pitfalls, and Payoffs, North Carolina State University.

George, J. and L. Jessup (1997). "Groups over time: what are we really studying?" Int J Human-Computer Studies 47: 497-511.

Gibbs, G. (1995). Learning in Teams, Oxford Centre for staff development.

Hartley, J. (1998). Learning and studying: a research perspective. London, Routledge.

Jaques, D. (1984). Learning in Groups. London, Kogan Page.

Jarvenpaa, S. and D. Leidner (1998). "Communication and trust in global virtual teams." JCMC 3(4).

Jessup, L. M. and J. Valacich (1993). Group Support Systems: New Perspectives. New York, Macmillan Publishing Company.

Lipnack, J. and J. Stamps (2000). Virtual teams: people working across boundaries with technology. New York, John Wiley.

Livingstone, D. and K. Lynch (2000). "Group project work and student-centred active learning: two different experiences." Studies in Higher Education 25(3): 325345.

Maznevski, M. and J. DiStefano (2000). "Global leaders are team players: developing global leaders through membership on global teams." Human Resource Management 39(2\&3): 195-208.

Millis, B. and P. Cottell (1997). Cooperative learning for higher education faculty, Greenwood Publishing Group.

Nickolls, F. (1993). "Prototyping: Systems Development in Record Time." the Journal of Systems management.

Salmon, G. (2000). E-moderating. London, Kogan Page.

Sheppard, K. and P. Dominick (2003). Preparing engineering students for the new business paradigm of international teamwork and global orientation. ECI Conference on Enhancement of the Global perspective for Engineering Studnets by Providing an International Experience, Tomar, Portugal, BEPress.

Tiwari and C. Holtham (1998). Learning Groupware through using groupware computer supported collaborative learning with face to face students. ITiCSE, ACM.

Tuckman, B. W. (1965). "Developmental sequence in small groups." Psychological Bulletin 63: 384-399.

Watson-Manheim, M. B., K. M. Chudoba, et al. (2002). "Discontinuities and continuities: a new way to understand virtual work." Information Technology \& People 15(3): 191 - 209.

Whatley, J., G. Staniford, et al. (1999). "Intelligent agents to support students working in groups online." Journal of Interactive Learning Research 10(3/4): 361-373.

Wooldridge, M. J., N (1995). Towards a theory of cooperative problem solving. 